\title{
CONTROLE QUÍMICO DO TOMBAMENTO CAUSADO POR Pythium aphanidermatum EM PLÂNTULAS DE MELÃO, PEPINO, REPOLHO E TOMATE
}

\author{
Flávia R. A. Patricio ${ }^{1}$ \\ Maria Elizabeth B. M. Lopes ${ }^{1}$ \\ Vanda M.A. Malavolta ${ }^{1}$ \\ Celso Sinigaglia ${ }^{1}$ \\ Nelson Peterossi Jr. ${ }^{2}$
}

\section{RESUMO}

Avaliou-se o controle químico de Pythium aphanidermatum, agente causal de tombamento nas culturas de melão, pepino, repolho e tomate. No colo de plântulas recém-emergidas dessas espécies foi colocado solo naturalmente infestado com Pythium aphanidermatum, obtido em área produtora de crisântemo ou gipsofila, misturado à farinha de aveia (20 g de farinha de aveia/litro de solo). A seguir, foram aplicados os tratamentos químicos, na forma de rega $\left(2 \mathrm{~L}\right.$ de calda $\left./ \mathrm{m}^{2}\right)$, que consistiram dos seguintes produtos e suas respectivas doses em g ou $\mathrm{mL}$ de produto comercial/100 L de calda: propamocarb hydrochloride (100), propamocarb hydrochloride (150), propamocarb hydrochloride (200), propamocarb hydrochloride $(100)+$ carbendazim $(100)$, propamocarb hydrochloride (150) + carbendazim (150), propamocarb hydrochloride $(100)$ + flutolanil (100), metalaxyl + mancozeb (300) e pentacloronitrobenzeno (600). Adotou-se o delineamento experimental inteiramente casualizado, com 4 repetições. Os tratamentos foram comparados pela porcentagem de plântulas sobreviventes ao tombamento, contadas três a sete dias após a aplicação dos fungicidas. Todos os trata-

1 Instituto Biológico - CEIB, CP 70, 13001-970, Campinas, SP.

2 Aventis CropScience Brasil Ltda. - Av. Maria Coelho Aguiar, 215 - Bl. "B" - $2^{9}$ Andar CEP 05804-902 - São Paulo - SP. 
mentos, com exceção do pentacloronitrobenzeno, reduziram o tombamento das plântulas de melão. Os tratamentos com propamocarb hydrochloride na maior dose e com metalaxyl+mancozeb resultaram em porcentagens de plântulas de pepino sobreviventes ao tombamento significativamente superiores às da testemunha. Nas plântulas de repolho todos os tratamentos, com exceção das misturas de propamocarb hydrochloride com carbendazin em um experimento e do pentacloronitrobenzeno em outro, proporcionaram controle eficiente de Pythium aphanidermatum. Apenas os tratamentos com propamocarb hydrochloride e suas misturas com carbendazin e flutolanil reduziram significativamente o tombamento das plântulas de tomate.

Palavras-chave: Brassica oleracea var. capitata L., Cucumis melo L., Cucumis sativus L., Lycopersicum esculentum L.

\section{ABSTRACT}

\section{CHEMICAL CONTROL OF THE DAMPING-OFF OF MELON, CUCUMBER, CABBAGE AND TOMATO SEEDLINGS CAUSED BY Pythium aphanidermatum}

Chemical control of the damping-off of melon, cucumber, cabbage and tomato seedlings caused by Pythium aphanidermatum was evaluated in soil naturally infested. This soil, collected in crisanthemum or gypsophila fields was mixed with oatmeal ( $20 \mathrm{~g}$ of oatmeal per soil liter) and placed around the stems of recently emerged seedlings. The chemical treatments, applied rightly after, were (with their doses in $\mathrm{g}$ or $\mathrm{mL} / 100 \mathrm{~L}$ of water): propamocarb hydrochloride (100), propamocarb hydrochloride (150), propamocarb hydrochloride (200), propamocarb hydrochloride $(100)$ + carbendazim (100), propamocarb hydrochloride $(150)+$ carbendazim (150), propamocarb hydrochloride (100) + flutolanil (100), metalaxyl + mancozeb (300) e pentacloronitrobenzen (600). The experimental design was completely randomized, with 4 replications. Three to seven days after the treatments, seedlings that survived damping-off were counted. All of the chemical treatments, except PCNB for melon, PCNB 
and metalaxyl+mancozeb for tomato, reduced seedlings damping-off. The higher doses of propamocarb hydrochloride and metalaxyl+mancozeb were the best treatments for cucumber seedlings. All of the chemical treatments, except the mixture of propamocarb hydrochloride with carbendazin and PCNB controlled cabbage seedlings damping-off caused by $P$. aphanidermatum.

Key words: Brassica oleracea var. capitata L., Cucumis melo L., Cucumis sativus L., Lycopersicum esculentum L.

\section{INTRODUÇÃO}

O tombamento de plântulas encontra-se entre as importantes doenças que incidem nas culturas de hortaliças e cucurbitáceas. Ocorre em geral em reboleiras e se caracteriza por afinamento do colo que resulta em queda e posterior morte das plântulas. (Flint, 1987; Messiaen et al.,1995; Ventura \& Costa, 1995). As perdas são resultantes da redução na população inicial de plântulas, na sementeira e no viveiro (Mizubuti \& Brommonschenkel, 1996).

Vários patógenos, como o oomiceto do gênero Pythium, podem estar relacionados ao tombamento. Na cultura do tomate, freqüentemente associadas ao tombamento e podridão de raízes, encontram-se as espécies: $P$. aphanidermatum, $P$. debaryanum, $P$. ultimum, $P$. myriotylum, e $P$. irregulare (Latorre, 1990; Mizubuti \& Brommonschenkel, 1996; Stephens \& Powell, 1982). Na cultura do repolho, várias espécies de Pythium foram citadas por Stephens \& Powell (1982) como responsáveis pelo tombamento de mudas, sendo $P$. aphanidermatum a mais patogênica dentre as espécies estudadas. O pepino, o melão e, de maneira geral, todas as cucurbitáceas são suscetíveis ao ataque por Pythium sp. e, em condições tropicais, a espécie que ocorre com maior frequiência é $P$. aphanidermatum (Messiaen et al., 1995). Esta espécie foi relatada por Stanghellini \& Phillips (1975) ocasionando severos danos na cultura do pepino em condições de alta temperatura, entre 28 e $36^{\circ} \mathrm{C}$, e também foi considerada a mais patogênica em cultivo de pepino em substrato, em casas de vegetação (Ranking \& Paulitz, 1994). Os plantios em casas de vegetação, princi- 
palmente em substratos artificiais, propiciam as condições ideais para o ataque por espécies de Pythium (Menzies et al., 1996).

Como medidas de controle recomendam-se evitar o plantio em épocas chuvosas e o excesso de irrigação, cultivar em solos leves, promover boa drenagem, utilizar sementes sadias ou tratadas e evitar adubações desbalanceadas (Rego, 1995; Latorre, 1990). Além dessas medidas culturais, o controle de Pythium spp. também pode ser obtido pela desinfestação de substratos com calor, brometo de metila e a aplicação de fungicidas nas sementes ou nas plântulas recémemergidas, antes e depois do transplante (Fletcher, 1984). Entre os fungicidas indicados na literatura internacional encontram-se metalaxyl, fosetyl-al ou cymoxanyl (Latorre, 1990). Produtos como propamocarb hydrochloride e metalaxyl, aplicados no solo, vêm sendo citados há vários anos nos Estados Unidos como eficientes no controle de Pythium (Meister, 1985).

No Brasil, entretanto, não existem fungicidas recomendados para o controle de Pythium spp. nas culturas de repolho, pepino e melão e somente para o tomate encontra-se registrado o produto mancozeb+metalaxyl (Ridomil-Mancozeb BR) para o tratamento de sementeiras (Kimati et al., 1997; Andrei, 1999).

$O$ recente incremento do plantio em casas de vegetação e também em lavouras muito tecnificadas, ambos com sementes de alto custo, têm aumentado a utilização de mudas de hortaliças e cucurbitáceas preparadas em bandejas. O substrato utilizado para o preparo dessas hortaliças não sofre tratamento fitossanitário e, em algumas condições, é reutilizado, tornando-se nesta situação sujeito à infestação por Pythium. Os plantios em casas de vegetação são intensivos e sucessivos, podendo acarretar também a concentração desse patógeno nesses locais (Fletcher, 1984). Considerando que há poucas alternativas para o controle de Pythium e a retirada do brometo de metila do mercado (Ristaino \& Thomas, 1997), o presente trabalho teve como objetivo verificar a eficiência de fungicidas ou mistura de fungicidas no controle do tombamento causado por Pythium aphanidermatum em plântulas de melão, pepino, repolho e tomate. 


\section{MATERIAL E MÉTODOS}

Avaliou-se o controle de Pythium aphanidermatum, agente causal de tombamento em plântulas de melão, pepino, repolho e tomate, em condições de casa de vegetação, no Instituto Biológico, em Campinas, SP, segundo metodologia adaptada de Lourd et al. (1986).

Seis experimentos foram instalados, sendo dois com a cultura do melão (novembro/1999 e fevereiro/2000), dois com a de repolho (dezembro/1999 e janeiro/2000), um com a de pepino (outubro/1999) e um com a de tomate (outubro/2001). Em todos os experimentos foi seguida a mesma metodologia.

Caixas plásticas com $20 \mathrm{~cm}$ de largura $x 30 \mathrm{~cm}$ de comprimento $\mathrm{x}$ $10 \mathrm{~cm}$ de altura, foram preparadas com 1,5 L de substrato desinfestado (autoclavado a $120^{\circ} \mathrm{C}$ por 3 horas) e umedecido. Utilizou-se como substrato solo coletado no Instituto Biológico, misturado a areia na proporção de três partes de solo para uma parte de areia. As sementes plantadas foram das seguintes variedades Redondo Gaúcho para melão, Caipira para pepino, Chato de Quintal para repolho e Santa Clara para tomate. Após a germinação realizou-se o desbaste, sendo mantidas 100 plântulas por caixa. $\mathrm{Na}$ fase de cotilédones abertos, uma mistura constituída por solo naturalmente infestado com Pythium aphanidermatum e farinha de aveia ( $20 \mathrm{~g}$ de farinha de aveia por litro de solo) foi adicionada sobre o colo das plântulas ( $0,5 \mathrm{~L}$ da mistura por caixa com 100 plântulas). Adicionou-se a farinha de aveia ao solo infestado para servir como fonte de nutrientes para o fungo, potencializando sua ação patogênica (Lourd et al., 1986). Nas culturas de melão, repolho, e pepino, empregou-se solo naturalmente infestado, coletado em Holambra, SP, em área produtora de crisântemo, e na cultura do tomate solo coletado de outra área do mesmo município, também plantada com crisântemo. Nas culturas de melão e repolho, que tiveram a instalação de um segundo experimento, foi também utilizado solo infestado, coletado no mesmo município, mas de área produtora de gipsofila (mosquitinho).

Imediatamente após a inoculação, foram aplicados os tratamentos químicos na forma de calda. Os tratamentos com seus respectivos 
nomes comerciais, princípios ativos, grupo químico e doses encontramse na Tabela 1. O delineamento estatístico adotado para todos os experimentos foi inteiramente casualizado, com 9 tratamentos e quatro repetições, com exceção do tomate, com 5 repetições, cada repetição sendo representada por 1 caixa com 100 plântulas. Quatro ou cinco caixas, referentes às repetições de cada tratamento, foram dispostas no chão em uma área delimitada de $1 \mathrm{~m}^{2}$, sendo a calda distribuída uniformemente sobre esta área por meio de regador, com a aplicação de 2 litros de calda $/ \mathrm{m}^{2}$. Cada plântula recebeu aproximadamente $1,2 \mathrm{~mL}$ de calda. No tratamento testemunha foi aplicada apenas água. Considerou-se como padrão o produto metalaxyl + mancozeb, registrado para tombamento provocado por Pythium sp. em tomate. Também foi incluído o pentacloronitrobenzeno, produto registrado para uso em sementeiras de hortaliças como alface, brócoli e tomate para controle de tombamento causado por outros patógenos.

Três a sete dias após a aplicação dos tratamentos, foi contado o número de plântulas tombadas, e determinada a porcentagem de plântulas sobreviventes ao tombamento.

\section{RESULTADOS E DISCUSSÃO}

Os resultados dos experimentos encontram-se na Tabela 2. Nos dois experimentos com plântulas de melão, todos os tratamentos apresentaram porcentagens de plântulas sobreviventes superiores à da testemunha, com exceção do pentacloronitrobenzeno, que resultou em maior tombamento que a testemunha. Não foram observadas diferenças significativas entre as três doses de propamocarb hydrochloride aplicadas. As misturas de propamocarb hydrochloride com carbendazim e com flutolanil também não diferiram entre si e em relação aos produtos isolados, assim como não diferiram do tratamento considerado como padrão, metalaxyl + mancozeb.

Os tratamentos com metalaxyl+mancozeb e propamocarb hydrochloride na maior dose proporcionaram o controle do tombamento em plântulas de pepino. Os demais tratamentos não diferiram estatisticamente da testemunha e, excetuando o propamocarb hydrochloride + carbendazim, foram semelhantes entre si. 


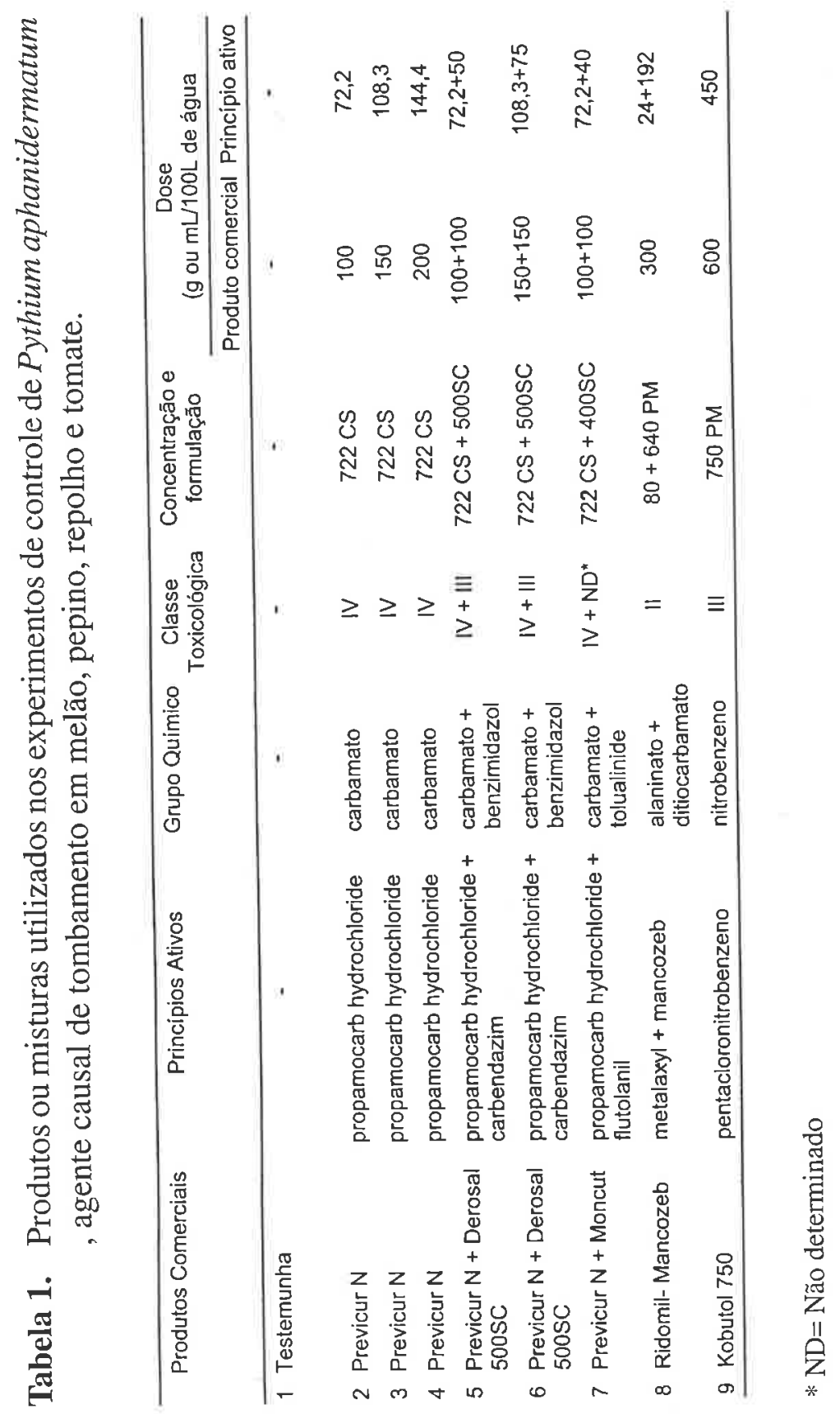




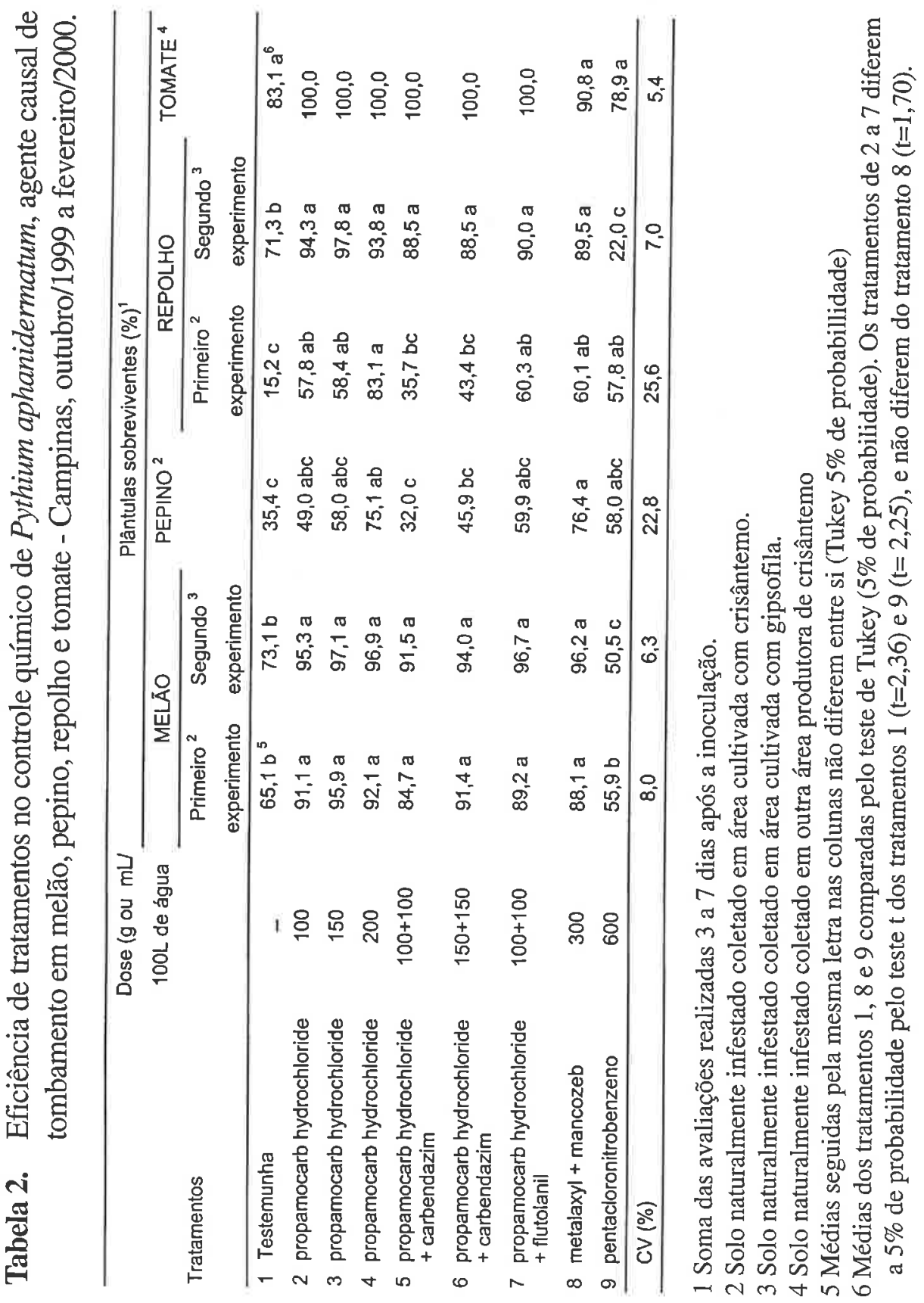


O maior número de plântulas de repolho sobreviventes ao tombamento no primeiro experimento foi apresentado pelo produto propamocarb hydrochloride na maior dose empregada. Este tratamento, entretanto, não diferiu estatisticamente daqueles realizados com propamocarb hydrochloride nas doses de 150 e $100 \mathrm{~mL}$, da mistura de propamoearb hydrochloride + flutolanil, do metalaxyl+mancozeb e do pentacloronitrobenzeno. Os tratamentos com misturas de propamocarb hydrochloride + carbendazim não diferiram da testemunha. No segundo experimento, todos os produtos apresentaram maior número de plântulas sobreviventes ao tombamento que a testemunha, excetuando-se o pentacloronitrobenzeno. Observou-se neste experimento que valores superiores a $90 \%$ de plântulas sobreviventes ocorreram nos tratamentos com propamocarb hydrochloride, nas 3 doses empregadas. Pode-se notar que, no primeiro experimento, houve uma elevada porcentagem de tombamento no tratamento testemunha, provavelmente devida às altas temperaturas ocorrentes durante sua execução, as quais favorecem o desenvolvimento de $P$. aphanidermatum, conforme relatado por Stanghellini \& Phillips (1975). Já o segundo experimento foi realizado durante um período em que predominaram dias nublados, com menor temperatura, o que provavelmente desfavoreceu o patógeno, e também os solos naturalmente infestados utilizados nos experimentos foram diferentes, provenientes de áreas cultivadas com crisântemo e gipsofila, respectivamente.

No experimento com tomate, os tratamentos 1,8 e 9 foram comparados pelo teste de Tukey ( $5 \%$ de probabilidade), não tendo diferido entre si. Os tratamentos com diferentes doses de propamocarb hydrochloride e as suas misturas com carbendazin e flutolanil (2 a 6) não apresentaram variância (média de 100\%), portanto foram comparados aos demais pelo teste t. Esses tratamentos diferiram da testemunha $(t=2,36)$ e do tratamento com pentacloronitrobenzeno $(t=2,25)$, mas não diferiram do metalaxyl+mancozeb $(t=1,70)$, considerado padrão, tendo resultado no controle do tombamento provocado por Pythium aphanidermatum nas plântulas de tomate. 
Observou-se nos experimentos com plântulas de melão, pepi no, tomate e no segundo experimento com repolho que o tratamento com pentacloronitrobenzeno resultou em porcentagens de plântulas sobreviventes menores ou semelhantes às das testemunhas. Ressalta. se que esse produto normalmente não apresenta ação fungicida efici. ente contra oomicetos, sendo indicado e registrado em diversas cultu. ras principalmente para o controle de tombamento causado $\mathrm{p}_{\mathrm{O}_{\mathrm{r}}}$ Rhizoctonia solani (Kimati et al., 1997; Morton, 1994). O tratamento com pentacloronitrobenzeno pode ter alterado o equilíbrio microbiano do solo, favorecendo o ataque por Pythium spp.

Em todos os experimentos realizados no presente trabalho, os tratamentos com propamocarb hydrochloride resultaram em número de plântulas sobreviventes superior ou equivalente ao do tratamento com metalaxyl+mancozeb, considerado como eficaz para oomicetos, como Pythium spp. (Morton, 1994). A menor dose de propamocarb hydrochloride $(100 \mathrm{~mL}$ de p.c./100L de água) avaliada foi suficiente para o controle do patógeno nas plântulas de melão, tomate e repolho no segundo experimento, efetuado com solo com menor infestação. No ensaio com plântulas de pepino, muito suscetíveis, e no primeiro experimento com repolho, em que as porcentagens de plântulas sobreviventes foram muito pequenas em ambas as testemunhas, indicando elevado potencial de inóculo, a dose de $200 \mathrm{~mL}$ de p. c./100L de água foi a mais adequada. As misturas não se mostraram vantajosas, provavelmente poryue o tombamento foi provocado apenas por $P$. aphanidermatum, e os produtos carbendazin e flutolanil não são indicados para oomicetos (Morton, 1994). Os resultados deste trabalho mostraram que o fungicida propamocarb hydrochloride pode ser mais uma alternativa, especialmente por ser do grupo dos carbamatos, diferente do grupo do metalaxyl, para o controle de Pythium aphanidermatum em áreas ou substratos infestados.

\section{REFERÊNCIAS BIBLIOGRÁFICAS}

ANDREI, E., 1999. Compêndio de defensivos agrícolas. $6^{a}$ Edição. São Paulo:Organização Andrei Editora Ltda. 672 p. 
COHEN, Y.; M.D COFFEY, 1986. Systemic fungicides and the control of Oomycetes. Annual Review of Phytopathology, 24:311-338.

FLETCHER, J.T., 1984. Diseases of greenhouse plants. Essex: Longman Group Limited. 335 p.

FLINT, M.L. (Ed.), 1987. Integrated pest management for cole crops and lettuce. University of California, Publication 3307, p. 57-76. KIMATI, H.; N. GIMENES-FERNANDES; J. SOAVE; C. KUROZAWA.; F. BRIGNANI NETO; W. BETTIOL, 1997. Guia de Fungicidas Agrícolas. Volume I - Recomendações por cultura. 2ª Edição. Jaboticabal: Grupo Paulista de Fitopatologia, 225p.

LATORRE, B.A. Cucurbitaceae, enfermedades, 1990. In: LATORRE, B; M.A. VAUGHAN; P.G. AGUILAR. Plagas de las hortalizas Manual de manejo integrado. FAO:Santiago, 520p.

LOURD, M.; M.L.B. ALVES; D. BOUHOT, 1986. Análise qualitativa e quantitativa de espécies de Pythium patogênicas dos solos no município de Manaus, I solos de terra firme. Fitopatologia Brasileira, 11:479-485.

MEISTER, R.T. (Ed.), 1985. Farm chemicals handbook '85. Willoughby: Meister Publishing Co., 538 p.

MENZIES, J.G.; D.L. EHRET; S. STAN, 1996. Effect of inoculum density of Pythium aphanidermatum on the growth and yield of cucumber plants grown in recirculating nutrient film culture. Canadian Journal of Plant Pathology, 18:50-54.

MESSIAEN, C.M.; D. BLANCARD; F. ROUXEL; R. LAFON, 1995. Enfermedades de las hortalizas. Madrid: Ediciones Mundi-Prensa, 576p.

MORTON, H.V., 1994. Chemical management. In: CAMPBELL, C.L.; D.M. BENSON (Eds.) Epidemiology and management of root diseases. Berlin:Springer-Verlag, p.276-292.

MIZUBUTI, E.S.G; S.H. BROMMONSCHENKEL, 1996. Doenças causadas por fungos em tomateiro. Informe Agropecuário, 18:7-14. RANKING, L.; T.C. PAULITZ, 1994. Evaluation of rhizosphere bacteria for biological control of Pythium root rot of greenhouse cucumbers in hydroponic culture. Plant Disease, 78:447-451. 
REGO, A.M., 1995. Doenças causadas por fungos em cucurbitáceas. Informe Agropecuário, 17:48-54.

RISTAINO, J.B.; W. THOMAS, 1997. Agriculture, methyl bromide, and the ozone hole. Can we fill the gaps? Plant Disease, 81:964-977.

STANGHELLINI, M.E.; J.M. PHILLIPS, 1975. Pythium aphanidermatum: its occurrence and control with pyroxychlor in the Arabian desert at Abu Dhabi. Plant Disease Reporter, 59:559. 563.

STEPHENS, C.T.; C.C. POWELL, 1982. Pythium species causing damping-off seedling bedding plants in Ohio greenhouses. Plant Disease, 66:731-733.

VENTURA, J.A.; H. COSTA, 1995. Doenças causadas por fungos em crucíferas. Informe Agropecuário, 17:53-56. 